\title{
Entre o perene e o novo: a apte de compreender o modismo educacional
}

\section{Ademir José Rosso}

Núbio Delanne Ferraz Mafra

Palavras-chave: formação de

professores; inovações

educacionais; educação. 
de uma arte? Em Fromm (1995, p. 17), podemos encontrar parte da resposta:

O processo de aprendizado de uma arte pode ser adequadamente dividido em duas partes: uma, o domínio da teoria: outra, o domínio da prática. Se eu quiser aprender a arte da medicina, devo primeiro conhecer os fatos a respeito do corpo humano e de várias doenças. Quando tiver todo esse conhecimento teórico, de modo algum serei competente na arte da medicina. Só me tornarei mestre nessa arte depois de grande prática, até que os resultados de meu conhecimento teórico e os de minha prática acabem por mesclar-se numa só coisa: em minha intuição, essência do domínio de qualquer arte. Além, entretanto, de aprender a teoria e a prática, há um terceiro fator necessário para que me torne mestre em qualquer arte: o domínio da arte deve ser questão de extrema preocupação; nada deve existir no mundo de mais importante do que essa arte.

Por entendermos que a teoria e a prática são indissociáveis e que constituem um par dialético na formação docente, discordamos da dissociação e da antecedência de um domínio sobre o do outro, seja ele teórico ou prático. Podemos então vincular o desenvolvimento dessa arte, necessária para compreender a novidade, à formação docente, apoiados no entendimento que as inovações e transformações pedagógicas somente podem repercutir positiva e de modo duradouro no contexto das práticas educativas se, como condição necessária, estiverem apoiadas sobre base teórica segura que passe pelo crivo do perene e do indispensável confronto com o contexto da prática educacional. Essa fundamentação, depurada no confronto com o perene, o constitutivo da educação, poderá dar ao educador a capacidade de distinguir: 0 nuclear, permanente, e o periférico ou impróprio ao ato educativo; o proveniente de uma demanda por aprofundamento e compreensão da sua função específica ou de tendências que negam a singularidade/ complexidade do ato educativo.

O termo modismo não possui um significado unívoco, variando na perspectiva das críticas internas ou externas ao universo das práticas escolares. A perspectiva externa serve-se mais do termo com o intuito de classificar e discriminar práticas docentes e orientações teóricas. Já a perspectiva dos professores pode significar insatisfação com o trabalho que executam, procura de alternativas, desejo de mudança, entre outros sentidos.

As análises do problema partem de diferentes perspectivas teóricas (Balzan, 1985; Garcia, 1996; Castelo Branco, 1991; Solé, Coll, 1997; Rego, 1998; Corazza, 1996) predominando as denúncias onde se reivindica: melhor formação teórica e crítica com a integração dos campos teóricos; práticas integradas aos campos teóricos e metodológicos; reconhecimento e respeito dos professores como sujeitos com saberes e experiências; diálogo na implementação de referenciais teóricos, metodologias e políticas educacionais.

Os fatores determinantes dos modismos, analisados da perspectiva docente, estão nas deficiências de natureza teórica, crítica e da função da educação. Numa perspectiva externa, estes fatores são submetidos às metodologias e referenciais teóricos de forma dogmática, superficial e acrítica. A formação docente poderia favorecer o aprofundamento, a análise e a crítica das inovações e referenciais teóricos. A tônica das críticas se dirige às políticas educacionais, aos órgãos governamentais e ao marketing dos milagreiros que invadem o campo educacional. De dentro do sistema educativo critica-se o sistema de formação por ser teoricamente deficiente e por mudar de marco teórico sem critérios e, quando trata das práticas, predominam aspectos metodológicos. As soluções apontadas passam pelo reconhecimento dos saberes docentes, de participação ativa dos professores nas decisões e eventos de formação continuada, na integração de campos teóricos e da teoria com a prática.

Em sentido pejorativo, esses contextos têm-se mostrado parciais, pois nem sempre tendem a considerar os educadores como produtores - algo original - , destacando mais o lado folclórico e as condições em que se manifesta o problema, sem considerar na mesma proporção as agências formadoras, os teóricos da educação e os projetos políticos para a educação. Mesmo que não intencionalmente, as críticas acabam desqualificando os docentes. Na realidade, essa é uma situação que envolve, de um lado, a forma - dirigismo ou diretivismo - como as novidades e as inovações são apresentadas pelos pesquisadores, teóricos e gestores educacionais e, de outro, como 
essas novidades são interpretadas e recebidas pelos educadores dentro da materialidade do espaço escolar.

Neste texto, modismo será entendido como mudanças súbitas, injustificáveis de prática e referências teóricas da educação, apoiadas em critérios de validade nem sempre suficientemente explorados teórico e praticamente. Por ser um fenômeno complexo, que se manifesta num conjunto de atitudes, idéias e práticas, é necessário mais que a descrição e o detalhamento; faz-se necessário buscar os elementos tanto de ordem mais geral quanto os mais profundos que se ocultam sob esta rotulação.

$\mathrm{Na}$ consideração da tensão entre os diversos fatores $e$ atores envolvidos nas novidades da educação escolar, no seu sentido mais amplo, pode-se admitir dois pressupostos amplos e complementares: 1) nem todas as distorções presentes no meio educacional provêm exclusivamente das más intenções e interpretações docentes ou que são originárias somente de suas cabeças; 2) nem todas as distorções encontradas no interior dos espaços escolares resultam única e exclusivamente de influências externas ao ato pedagógico. Esses pressupostos, na opinião de Balzan (1985, p. 89), constituem um paradoxo, em que

Nossos problemas são sentidos em sala
de aula, mas suas soluções não podem
ser pensadas exclusivamente a este ní-
vel, não podem ser circunscritas ao pro-
cesso de ensino e aprendizagem e nem
mesmo ser passíveis de solução, se en-
tendidas no âmbito exclusivo da área
educacional. Trata-se de um paradoxo:
"nós os detectamos a nível de sala de
aula, que podemos agir. Porém nossa
ação somente terá sentido se entender-
mos que eles não estão exatamente aqui".
Aprender este paradoxo me parece ser a
condição primeira para a superação do
atual estado de coisas (grifos do autor).

Entre os extremos do paradoxo, localiza-se, de um lado, a competência necessária e a responsabilidade política assumida pelo educador, que agindo dentro de um espaço social, trabalha dentro de uma ordem social, podendo conformar-se e submeter-se, reproduzindo-a, ou, ao contrário, trabalhando para a sua mudança; de outro, as agências gestoras da educação e formadoras dos educadores possuem responsabilidades que não podem ser simplesmente transferidas para os professores. Se o primeiro pressuposto estabelece créditos aos professores, quando leva em consideração as condições adversas de trabalho e a (in/ de)formação recebida, o segundo, ao afirmar que a prática pedagógica não é hermética e nem imune às influências externas à educação, cobra do educador responsabilidade no desempenho de atividades específicas e necessárias ante os educandos.

$\mathrm{Na}$ discussão do tema, foi difícil filtrar as fontes a partir de um campo teórico específico. Por isso, o desafio reflexivo que nos propomos passa pela análise de materiais heterogêneos, procurando sistematizar essas alusões diversas, buscando a lógica implícita nessas denúncias, compreendendo alguns dos meandros que subsidiam atitudes e práticas que redundam na configuração dos modismos. Ao descrevermos os males presentes nos modismos pedagógicos, temos a consciência de que eles se inscrevem dentro de uma prática cultural onde os professores, apesar de sentirem, nem sempre possuem o conhecimento de todas as variáveis intervenientes. Não basta negar a moda, ou criticar seus aspectos mais aparentes, atacando os professores; é necessário proceder uma análise que possibilite o desmonte e sua superação.

A superação trabalharia no sentido de fazer o educador canalizar energias, compreender o significado presente nessa aparente volatilidade como portadora de, num primeiro plano, um clima favorável e aberto às inovações. A caminhada do educador acometido pelo modismo partiria de uma atitude dominada por fatores afetivos e voluntariosos em direção de uma atitude mais objetiva, apoiada nos dados disponíveis nas ciências da educação, possibilitando a compreensão dos objetivos da educação, da escola e do papel do próprio professor. Com isso, resguardam-se os professores do ataque desqualificante promovido por se portarem de maneira heterodoxa e eclética diante das formulações teóricas. Ao mesmo tempo, afirmase a necessidade de um tempo e de um espaço de ação que possibilitem o estudo, a reflexão e a pesquisa; uma formação consistente que compreenda o profissional da educação como sujeito autônomo capaz de implementar uma prática lúcida comprometida. Isso tudo sem deixar de considerar as condições objetivas de trabalho, de salário, respeito profissional, etc. 


\section{Estabelecendo contornos}

Analisar os modismos pedagógicos como um fenômeno inscrito dentro de uma prática cultural significa levantar os valores que perpassam essa cultura. Tal prática cultural apóia-se nos valores do mercado onde, para ela, os valores predominantes são o do consumo e do oferecimento de serviços. Para o mercado, as relações sociais se desenrolam na perspectiva do prestador de serviço e cliente, tendo como metas a satisfação do cliente e o lucro do prestador do serviço. Pela origem histórica e princípios filosóficos, as metas perseguidas pelos ideais educativos professados, a relação educativa e formativa se desenvolve dentro de objetivos diferentes.

A seguir, passaremos a analisar a forma como se processa essa prática cultural a partir da ótica do consumo descrita por Baudrillard. Para ele, "todo o discurso (...) acerca do consumo articula-se na seqüência mitológica de um conto: um Homem é dotado de necessidades que o impelem para objetos, fontes de sua satisfação" (Baudrillard, 1991, p. 68; grifos do autor). O seu desejo é insaciável por estar fundado na lógica social do inconsciente, da carência. Este desejo é insolúvel para sempre, promovendo fuga para frente e a renovação ilimitada das necessidades.
A mentalidade de consumo (...) permite arriscar a seguinte comparação: é o pensamento mágico que governa o consumo, é uma mentalidade sensível ao miraculoso que rege a vida quotidiana, é a mentalidade primitiva (...) definida como baseada na crença na omnipotência dos pensamentos.

As necessidades visam mais aos valores que aos objetos e a sua satisfação possui em primeiro lugar o sentido de uma adesão a tais valores. A escolha fundamental, inconsciente e automática do consumidor é aceitar o estilo de vida de determinada sociedade particular (Baudrillard, 1991, p. 21, 69-70; grifos do autor).

O milagre possibilitado pela multiplicidade de signos possibilita ao consumidor a exclusão maximal do mundo real, social e histórico, tendendo para a felicidade, eliminando tensões, angústias e sacrifícios.

A moda, como um dos elementos mais proeminentes da sociedade de consumo, instala-se principalmente com o auxílio da propaganda especializada em pressionar e criar necessidade de consumir-se um determinado produto. $\mathrm{Na}$ sua consecução, todo o aparelho econômico e psicossociológico de estudos de mercado e de motivações são mobilizados para fazer reinar no mercado a procura real e para criar ou se adequar às necessidades profundas do consumidor. As necessidades criadas são tanto mais eficientes quanto mais se encaixarem nas lacunas pessoais e estereótipos sociais. Quanto mais naturais parecerem, mais facilmente conquistarão a adesão e o apoio das pessoas. Dessa maneira, controla-se o comportamento do mercado, dirigindo e configurando as atitudes sociais e necessidades pessoais.

Esta situação pode ser descrita de forma mais sucinta, ainda nas palavras de Baudrillard (1991, p. 60), ao afirmar que: 
Nunca se consome o objeto em si (no seu valor de uso) - os objetos (no sentido lato), manipulam-se sempre como signos que distinguem o indivíduo, quer filiando-o no próprio grupo tomado como referência ideal, quer demarcando-o do respectivo grupo por referência a um grupo de estatuto superior. (...) Cada indivíduo vive os lucros sociais diferenciais como lucros absolutos e não o constrangimento estrutural que está na origem da permuta das posições e da pertinência de ordem das diferenças.

A contradição e o embuste estão na impressão de o produto harmonizar-se com as necessidades do indivíduo, encaixar-se na fome psíquica e responder às necessidades mais secretas de ser moderno, atualizado, bem-sucedido, etc. "O que se é" ou "o que se pensa" desloca-se para segundo plano; o que importa é "parecer" ou "ter a posse da novidade", mesmo que o produto seja uma "prótese cerebral" e não tenha nada a ver com evolução mental. Na moda, o critério de validade é extrínseco e coercivo e, apesar da mistificação das promessas do preenchimento das lacunas individuais, da liberdade e da soberania, busca-se outro objetivo nãorevelado. Esses valores prometidos não passam de mistificação - o que se quer, normalmente, é a venda do produto.

Neste contexto de manipulação cínica do inconsciente, restam ao indivíduo a decepção e o vazio não-preenchidos pelas promessas que lhe pareciam tão eficazes e ajustadas às suas necessidades. Decepcionado, sem perspectiva e orientação pessoal, torna-se presa fácil de uma nova proposta/aposta de um novo produto, jogando para frente mais uma vez as reais possibilidades de crescimento pessoal, da busca de um significado para a sua vida. Dessa forma, o indivíduo vai sendo empacotado, enrolado como os produtos - valores e signos vazios - que adquire sem, entretanto, responder às necessidades intrínsecas que são de outra natureza.

A relação moda-consumo com os modos de produção e de venda é um dos fatores que possui grande influência na estruturação da sociedade como um todo e suas ligações são pouco transparentes. Baudrillard (1991, p. 180) ainda afirma que:

Entrar no ciclo do consumo e da moda não é apenas rodear-se de objetos e serviços a seu bel-prazer, é mudar de ser e de determinação. É passar de um princípio de autonomia - o caráter, o valor do próprio eu - para um princípio de reciclagem perpétua pela indexação num código em que o valor do indivíduo se faz racional desmultiplicado e mutável: é o código da "personalização", de que nenhum indivíduo em si é depositário, mas que atravessa cada indivíduo na sua relação com significados outros.

Nos mais diferentes campos de saber, encontramos reflexões combatendo modismos. Nas neurociências, por exemplo, Del Nero (1997, p. 17 e 450) denuncia "os aproveitadores que, sob o rótulo de 'científico', vendem idéias parciais e erradas (...) beneficiando-se da ingenuidade" e "da má capacitação cognitiva (...) [dos indivíduos] (...) para ludibriá-los com supostas curas quando, na verdade, oferecem apenas emplastros". Por isso, mais do que a delimitação de um campo teórico, o que une tais informações é o problema, as suas manifestações e o ambiente propício ou criado para a implantação dessas idéias sob o rótulo de científicas e modernas.

Ainda para Del Nero (1997, p. 451),

... a garantia de que não nos tornemos (...) desejantes do último lançamento (...) é associarmos à liberdade, ao respeito e à opinião, como valores máximos, uma formação sólida de valores, conhecimento, mundo interior, atividade racional e estrutura clara de deveres.

A formação de professores, apesar de levantar-se como grande esperança dos avanços educacionais, por vezes, além do razoável, ainda não consegue abarcar os atributos levantados nestes comentários.

No meio educacional, são comuns as perspectivas evolucionistas lineares de análise (Puiggrós, 1997) e historicista, onde sempre o momento presente é superior ao do passado, graças aos teóricos iluminados do presente que o constroem. Sobre essa mentalidade, Garcia (1996, p. 37) chama a atenção que "a literatura educacional no país enfatiza o fracasso das concepções passadas e da maioria dos planos de desenvolvimento". Mais adiante (idem, ibidem, p. 40), continua: "o sistema educativo, vez por outra, é tomado de assalto por milagreiros que propõem desde computadores para alfabetização até campanha para 'erradicação do analfabetismo' sem nenhum compromisso maior de compatibilizar meios adequados para os fins que anunciam". 
Muito interessante é o estudo de Cunha (1995) que, ao retornar às fontes históricas para analisar os escritos de Fernando de Azevedo e Anísio Teixeira, entre outros do movimento da Escola Nova, conclui o quanto é inadequado, insuficiente e superficial o rótulo de psicologismo ao pensamento escolanovista. Sob a lente de seus professores, que citam a classificação das concepções pedagógicas, os acadêmicos lêem muitas vezes aqueles atores da educação brasileira como responsáveis pelo atraso, individualismo e psicologismo da educação. Transformam-se, em suma, no pó da educação. É claro que o mais moderno e mais avançado passa a ser a idéia contemporânea, da qual estes acadêmicos são os seus melhores representantes. Os educadores que não provarem esse pedigree teórico terão poucas chances em muitos foros educacionais.

Quem tem ousadia suficiente para citar, discutir e contextualizar algumas das idéias desses professores, ou se são eles os responsáveis pelas práticas enviesadas dos atuais profissionais em educação?

Costa (1997, p. 208), na introdução de um artigo que faz uma crítica da análise economicista da educação, lista alguns pontos negativos marcantes nos modismos que servem de ponte para as discussões da seção seguinte:

- sua aceitação muito fácil e muito rápida pela maioria dos especialistas de sua área, que muitas vezes sequer conhecem bem a teoria que os suporta e que, certamente, não a colocaram sob o crivo de uma análise mais crítica cuidadosa, antes de esposarem-nos;

- o uso de um jargão novo, que serve, principalmente, para agrupar os iniciados em torno de algumas palavras-chave, formando "igrejinhas" fechadas e segregando-os dos que ainda resistem a aceitar os novos dogmas;

- o entusiasmo com que os modismos são recebidos nos círculos que os aceitam e as enormes e exageradas esperanças que neles depositam seus seguidores;

- a generalização do emprego de seus conceitos principais, fazendo com que eles passem a ser uma espécie de panacéia ou "Maravilha Curativa", remédio de uso universal, eficiente para quaisquer tipos de contusões;

- a sua defesa, feita por seus adeptos com um misto de fé e fervor religioso, em lugar de argumentos científicos ou lógicos, o que os transforma numa espécie de sacerdotes de uma nova religião; - o proselitismo, que leva cada um de seus defensores a se comportar como um apóstolo caçador de filiações para a causa; e - a repulsa de seus adeptos fervorosos contra os que só aceitam parcialmente ou os que simplesmente não aceitam e a verdadeira fúria com os que investem contra esses.

Assim que passam os modismos, "os intelectuais sérios podem juntar os cacos que sobraram de sua destruição e, muitas vezes, reabilitar aspectos realmente importantes das teorias que os suportavam, que, provavelmente, ainda permanecerão vigorando por longos períodos".

Por isso muitas teorias retornam a discussão, não apenas pelo relançamento ou necessidade de renovação da moda, mas porque muitas pessoas e grupos de pesquisadores vão além do capricho pessoal ou da coerção do meio social em momentos que estava fora de moda estudar certos aspectos teóricos. São pesquisadores dedicados que continuaram os seus trabaIhos de investigação, fazem escola, formam discípulos - atingindo maturidade, consistência teórica e ultrapassando o fenômeno sensível de massa. Por isso voltam com maior vigor e profundidade. A retomada da discussão de um marco teórico no universo escolar por certo contém uma dose de fenômeno cultural coercitivo, mas não é possível ignorar a existência de pessoas que continuam trabalhando com afinco, avançando no sentido de iluminar a prática escolar, ultrapassando os efeitos das sazonalidades teóricas.

$\mathrm{Na}$ condição de quem está preocupado com o crescimento profissional dos educadores e busca entender o porquê de determinadas posições, podemos perguntar: qual é a lógica interna do professor que sobrevive nas suas funções, apoiado nos modismos pedagógicos, e quais são os germes, os potenciais reais de crescimento, os desequilíbrios que poderemos extrair para conduzi-lo a uma prática pedagógica mais efetiva? Por que as possibilidades de mudanças são avaliadas como exteriores ao seu fazer pedagógico? Por que o professor não é capaz de assumir uma atitude crítica? 


\section{Destacando alguns contextos}

Uma vez percorridos os caminhos em que se esclareceu a origem e abordagem da temática, passamos pela análise da prática cultural do consumo. Discutiremos a formação do artista/professor ante os contextos de mudanças teóricas e de políticas educacionais.

Retomando o significado da arte apontado por Fromm (1995, p. 17), transpondo e adaptando para a arte de compreender a novidade, podem ser destacadas, na formação docente, três esferas que interagem no desenvolvimento desta arte. Vamos considerá-las como esfera teórica, esfera prática e esfera política. Começaremos a discussão pela esfera política das políticas para educação ou, no dizer de Fromm, aquilo que se constitui como a "extrema preocupação", onde "nada existe de mais importante" do que a sua execução.

Tomemos, como exemplo, a nova Lei de Diretrizes e Bases da Educação Nacional (LDB). Apesar de ser uma discussão que tenha durado quase duas décadas, ficou no ar a sensação de que essa discussão não esteve próxima da ampla maioria dos professores que estão trabalhando no ensino fundamental, médio e superior. Uma vez aprovada com uma série de críticas e restrições, deu-se início ao processo de implantação a partir dos Parâmetros Curriculares Nacionais (PCNs), avaliações e medidas similares. Para o professor que está em sala de aula, atolado em carga horária e que recebeu uma formação que se choca com muitos dos elementos apontados - como, por exemplo, "interdisciplinaridade", "temas transversais", "provão", dentre outros - estas discussões inserem-se num terreno absolutamente distante e alheio a ele.

Objetivamente, esse preceito legal cria uma demanda de estudos, reuniões, etc. que conseguem, nas atuais condições de trabalho, carga horária, salário, etc., sensibilizar, no máximo, o grupo dirigente e controlador das políticas e práticas educacionais. Qual educador amarrado a um vínculo empregatício de sobrevivência e subserviência assumirá tal princípio? Com certeza, vários professores passam a escrever muitos dos termos acima citados em seus planos de trabalho e nas discussões com os colegas, mas o que efetivamente fazem em sala de aula poderá ter muito pouco a ver com a dita interdisciplinaridade (Lenoir, Larose, 1998).
Mesmo assim, muitos professores fazem um esforço sincero, têm idéias criativas e conseguem avanços de natureza intuitiva em suas práticas, ainda que a despeito de uma reflexão teórica mais consistente ( $\mathrm{Fa}$ zenda, 1999). Se esta é uma questão que, do ponto de vista acadêmico, já suscita muitas discussões e controvérsias, é possível imaginar as mais diferentes interpretações pelas quais esta sugestão ou imposição legal passará no decurso dos próximos anos. A pergunta que se faz é: como implementar práticas e metodologias de ensino que passem pela interdisciplinaridade, mantendo-se as atuais condições de trabalho docente?

Como situação proveniente da esfera política que tem como alvo a prática docente, esta implantação não pode prescindir de discussões teóricas que possibilitem a compreensão de sua importância nas práticas escolares. Se politicamente deseja-se com extrema preocupação, não existindo nada de mais importante do que a sua execução, há de se considerar as condições materiais de sua implantação. Caso contrário, cai-se na ilusão de que bastam os cursos, os treinamentos e as avaliações e outras formas de pressão para a sua implementação.

Neste caso, as mudanças esperadas pelas políticas públicas - umas mais explícitas, outras menos - não acontecem pela ausência de condições práticas. Na ilusão prepotente de que basta o treinamento, acusa-se o professor de não aplicar ou digerir competentemente o remédio receitado. Não se trata de atacar e ridicularizar os professores sacrificados e anônimos que, sob pressão do contexto escolar, esperam encontrar uma saída, uma resposta às suas indagações e aos seus problemas. Agir dessa forma é culpar, desautorizar e desqualificar os professores por algo que não depende diretamente e somente deles. Há que se responsabilizar, sim, os lançadores de facilidades que exploram ou fingem ignorar as carências dos educadores e da educação para promoverem emplastros e/ou produtos de consumo para a educação.

Os responsáveis por tais políticas não estão muito longe da prática dos gurus lançadores de moda que investigam com muita competência as necessidades mais recônditas dos consumidores. No universo educacional - guardadas as devidas proporções e intencionalidade - temos também situações e promotores de modas 
que exploram as carências dos professores, vendendo livros, conferências, cursos, projetos, etc. É contra esses fabricantes de facilidades e de soluções salvadoras que devemos estar alerta.

Há que se considerar também, como integrante do campo político, os movimentos de forças existentes no interior da própria categoria, como corporação social, organização sindical, entre outros, que influem tanto nas tomadas de posições, enquanto categoria, quanto de práticas individuais. Ao contrário do que parece, não se trata de um campo social homogêneo, disforme ou consensual. No espaço escolar existe uma verdadeira rede de produção de sentidos em relação ao trabalho, docentes, práticas escolares e sociais. Nessa rede de relações, estão constantemente em disputas concepções e forças políticas e ideológicas associadas ou não ao conjunto dos movimentos sociais.

Do ponto de vista da formação docente, tem significado político especial a oposição entre formação e trabalho que se expressa dentro das licenciaturas na separação entre teoria e prática, tal como operário separado dos meios de produção, da cultura e da sociedade civil. Por isso, avançar em termos concretos nesse terreno pode significar também uma meIhor preparação política dos educadores como categoria social. Tal como vem sendo denunciada nas pesquisas (Maldaner, Schnetzler, 1998; Silva, 1997), a formação docente tem contribuído para a alienação e exploração profissional dos formados nos cursos de licenciaturas.

Considerando os rumos seguidos pelas políticas educacionais, os professores tiveram pouco espaço para expressar e fazer valer suas vontades políticas. As manifestações mais expressivas são por meio de intérpretes, formas variadas de resistências ou por escamoteamento de posições reais.

Considerar a esfera das práticas docentes, interagindo com a esfera teórica e a esfera política é buscar elementos de discussão e confronto a partir do enfoque historicamente mais descuidado na formação docente. Considerar o campo prático como constitutivo da formação docente e integrado a outras esferas formativas significa considerar as esferas da formação docente como o aprofundamento teórico dessas práticas e também das práticas que questionam e crivam teorias e políticas. A ótica da racionalidade técnica sempre rechaçou a consideração desse campo, pois esses saberes, do ponto de vista de um estatuto epistemológico, se constitui um problema com desdobramentos não tão fáceis de se justificar.

Se no campo da prática pedagógica emerge um comportamento mutante, este comportamento pode muito bem refletir um desejo sincero de mudança, expresso de maneira sensível pela insatisfação e pela percepção genérica de que as coisas como se apresentam não estão bem. Esse malestar geral pode estar aliado ao imperativo de consciência de que é preciso fazer algo, mesmo que não se saiba ao certo ainda o quê e como fazê-lo.

Apesar da adversidade e da aridez desgastante que caracteriza a rotina pedagógica deste proletarizado professor (Mafra, 1998), encontramos um bom número de docentes que emergem, em determinados momentos, pela tomada de consciência, questionando-se sobre o ato educativo e buscando solucionar os problemas, mesmo que não muito claramente definidos. Apesar de o problema ser apenas percebido na sua periferia, pelos sintomas, sem ser compreendido e pensado como tal, se constata que, mesmo nestas condições, muitos professores, mais por intuição do que por conhecimento, ainda conseguem ultrapassar a vala comum da mediocridade e executam uma prática pedagógica diferenciada, fundamentada em princípios educacionais.

Isso por si só já abre a possibilidade da investigação. Essa lógica da ação, mesmo que envolta em posições teóricas pouco consistentes ou na onda de uma novidade teórica, pode favorecer o surgimento de novas posições práticas, pois, como afirma Costa (1990, p. 369), "de um lado o modismo exerce um papel positivo, na medida em que enfatiza certas posições e idéias, de outro, ele inibe ou dificulta uma postura mais profunda do problema em discussão" pela carência de aprofundamento teórico ou de um confronto mais sério com a prática.

O mecanismo de pressão e da novidade motiva e induz o comportamento, mas não garante, na mesma proporção, o pensamento e a compreensão em profundidade dos problemas que se tem. É difícil um problema percebido no nível superficial ser resolvido de forma consistente sem o envolvimento do professor em todos os seus

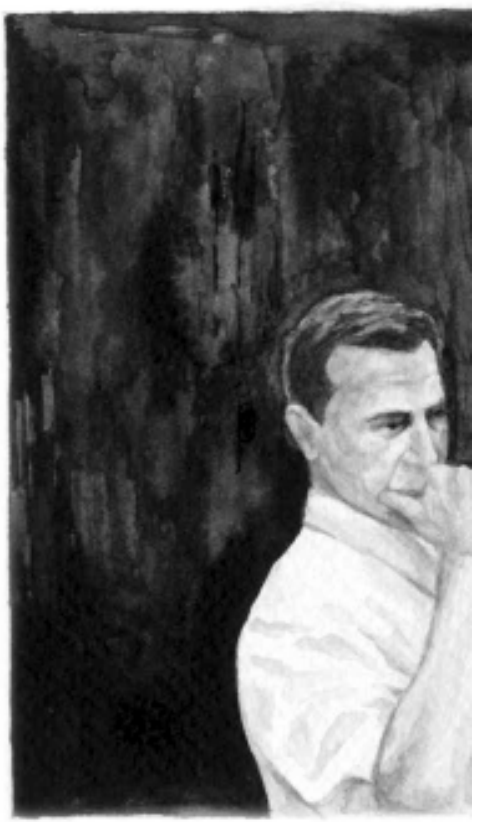


níveis de consciência. Para mudar é necessário buscar as raízes, pois nenhuma transformação substantiva em educação prescinde do envolvimento pessoal dos educadores. De acordo com Bachelard (1996), é necessário passar por uma psicanálise dos obstáculos que emperram uma melhor compreensão teórica e prática.

De alguma forma, o mal-estar gerado funciona como incentivo à mudança e a iniciativas de cunho intuitivo. Na busca ou na ânsia de sair do sufoco, mas sem um rumo certo, o professor pode agarrar-se à primeira tábua de salvação e/ou legitimação que se apresente mais atraente ou que demande menos esforço. Mesmo assim, por questão de incompreensão, de tempo disponível e de economia de energia, acaba por não assumi-la integralmente e de forma consciente.

Ao serem confrontados os dois pressupostos pontuados na introdução do artigo, analisando a complementaridade necessária entre análises internas e externas da educação, com o fracasso escolar, é oportuno também, como afirmam Carraher,

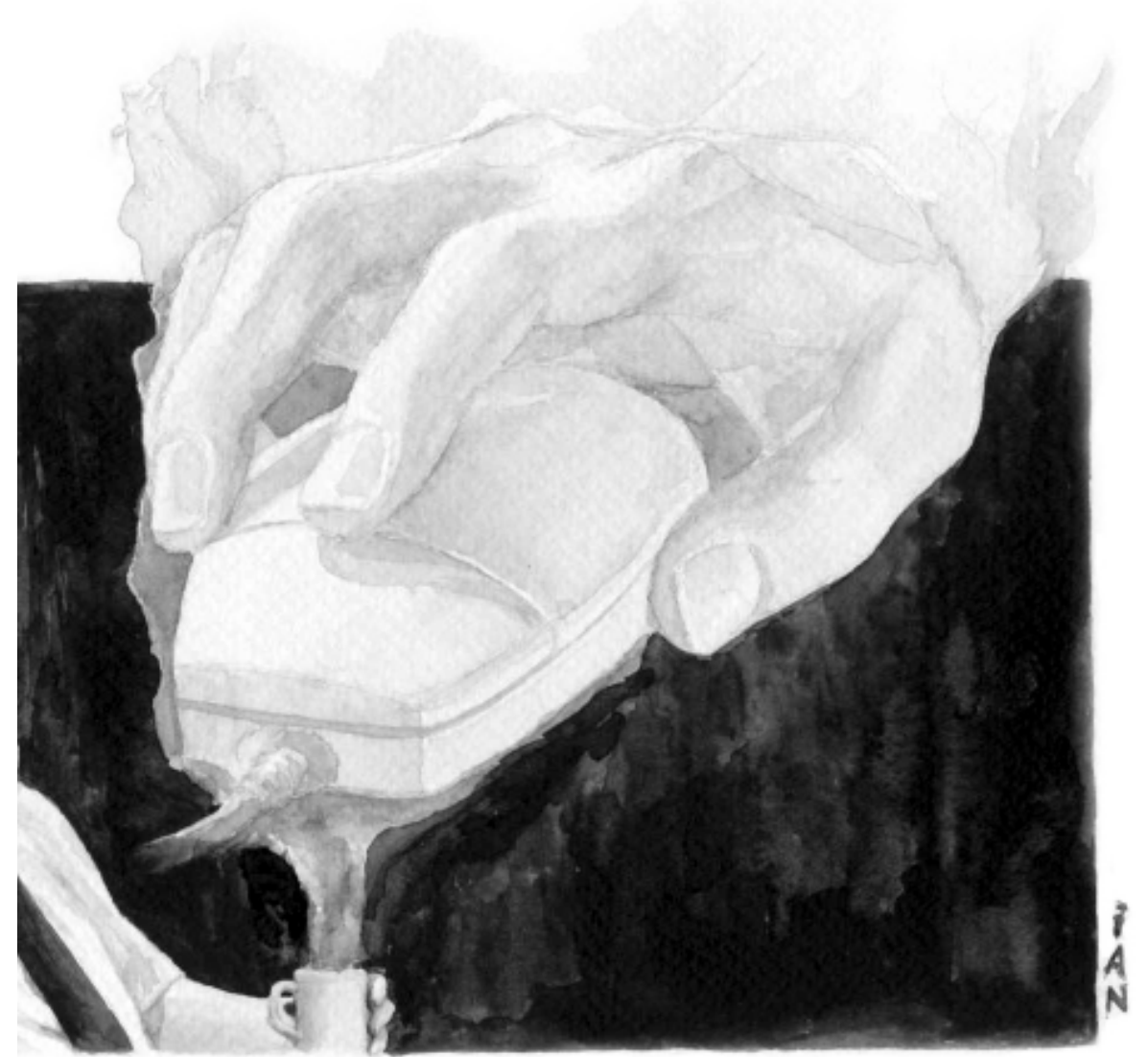

R. bras. Est. pedag., Brasília, v. 81, n. 197, p. 50-63, jan./abr. 2000.
Carraher e Schliemann (1991), pensarmos a escola a partir da sala de aula, assumindo o fracasso da escola em si, a partir das práticas escolares. Devemos discutir a escola e o seu fracasso de dentro para fora, pois é na sala de aula que se decide e se concretiza o sucesso ou o fracasso do aluno. Isto não significa que os fatores externos não influenciem ou condicionem os resultados dos alunos; significa, isto sim, que, isoladamente, eles explicam apenas parte do fracasso. Assim entendida, a evasão e a repetência não são somente resultantes, entre outras causas, do fracasso dos indivíduos/alunos ou de classes sociais ou da economia, mas resultam também do fracasso da escola e de seu projeto pedagógico.

Ao analisar os pensamentos dos professores em relação às diferenças, Rego (1998, p. 70) afirma que os professores se encontram "imersos em uma rede de informações teóricas de senso comum" e aponta que "a formação eclética parece acarretar certo amadorismo, uma tendência de reproduzir (ou rejeitar) o modelo fornecido por antigos professores, tendo como pressuposto sua intuição ou o senso comum" (idem, ibidem, p. 53).

Tal conclusão se aproxima das informações que foram coletadas por Rosso e Etges (1999) com 115 professores sobre o conceito de educação. As informações indicam que não existe uma diferença significativa no conceito de educação entre os formados em áreas de Ciências Humanas, como Pedagogia e História, por exemplo, em oposição aos da Área de Ciências e Matemática. Os autores chegam à conclusão de que as disciplinas pedagógicas influem muito pouco na expressão um conceito mais preciso sobre educação por parte dos professores. Quem está dirigindo a formação do conceito de educação é o senso comum pedagógico povoado de discursos das mais diferentes ordens.

Conclui-se existir um hiato entre a esfera teórica com a prática, inadequação de referenciais teóricos com o contexto das práticas escolares, sobreposição de determinado campo teórico sobre os demais e fundamentos teóricos insuficientemente aprofundados porque estão dissociados da pesquisa. Toda vez que se pretende sobrepor um elemento de abordagem sobre os demais elementos da formação dos professores, acaba-se criando um "remédio" com um espectro de cura mais amplo do 
que realmente é capaz de atingir. A educação e a formação de educadores resulta de um esforço interdisciplinar, de cada ciência bem fundada, de todas as ciências que têm contribuição a prestar. É, no mínimo, pretensiosa a situação em que uma única abordagem tenta se sobrepor às demais. Quando se trata de um fenômeno complexo e multideterminado, uma abordagem exclusiva não consegue dar conta de contemplá-lo em sua totalidade.

Apesar das metas confessadas pela educação serem radicalmente diferentes do sistema de produçãa-consumo, o universo escolar funciona dentro dele e tem suas condições objetivas moldadas pelo sistema. Se a escola trabalhar de maneira alienada ou exclusivista, fracionando conhecimentos e a compreensão de si própria, sem considerar a "multidimensionalidade do processo" educativo (Candau, 1985, p. 21), estará somente a serviço deste mesmo sistema.

A doutrinação proveniente dos falsos valores ou de valores superficialmente discutidos reforça o ciclo de dependência e desvia a ação docente dos seus fins. Quem ganha com essa prática são os que da moda se beneficiam. Dessa prática se esperam os piores resultados e o máximo que se consegue é transformar as pessoas sofridas e com uma formação inadequada em subordinadas e dependentes, ou avessas e impermeáveis a qualquer inovação.

Estrategicamente, para se livrarem de rotulações que consideram os professores como "algozes incompetentes" (Silva, 1997), assume-se em público e entre os colegas "ares de", e o que realmente acontece entre as quatro paredes da sala de aula não interessa. Se politicamente são inúmeras as práticas que sistematicamente desqualificam os docentes, assumir "ares de" camufla a mediocridade pedagógica. Associada à indiferença social e à defesa muitas vezes incondicional dos colegas e superiores feita em nome do bom andamento da escola, esta postura esconde o que acontece em sala de aula. Nestas situações, o discurso dito "progressista" é legitimado/negado/distorcido por uma prática pedagógica contraditória e desencontrada.

Por isso, no que se refere à atuação dos professores, torna-se previsível saber por que os educadores constantemente mudam ou simulam mudar a direção e os objetivos/intenções educacionais; por que os educadores assumem com certa facilidade um discurso pedagógico progressista, mas mantêm-se presos a práticas educativas tradicionais; por que alguns professores fazem questão de se apresentar e parecerem modernos, simulando conhecer e aplicar determinadas teorias, quando suas práticas reais estão longe desses modelos teóricos confessados.

Dentro do contexto das práticas culturais e da pressão, nada incomoda mais esses professores do que o fato de não conseguirem se encaixar numa rotulação em voga. De forma alguma querem parecer ultrapassados e receber o rótulo de conservadores, alienados, antiquados, etc. Isso vai contra tudo o que se acreditou ser nos últimos tempos o ideal do trabalho educativo da chamada teoria histórico-crítica. $\mathrm{O}$ fato de se estar na crista da onda pedagógica ainda que surfando sobre detalhes carentes de significado ou marcados por um enfoque exclusivista e distorcido - torna-se, aos olhos dos incautos, sinal de uma situação de elevado prestígio.

\section{Considerações finais}

Ante a vulnerabilidade que representa o "ser professor", quando tudo parece estar conspirando contra nós, reconhecemos que o assumir-se como um educador não é uma decisão das mais fáceis. O ponto de indignação que levantamos contra a moda é a atitude tripudiante de se aproveitar justamente desta fragilidade/carência, depreciando e negando a participação e a autoconstrução dos sujeitos/agentes da educação, buscando contabilizar dividendos tanto econômicos como político-ideológicos, pressionando e buscando o consenso dos educadores.

A vulnerabilidade dos professores ante as idéias e os conceitos superficiais - nem sempre suficientemente aprofundados ou que não foram desenvolvidos especificamente "no" e "para" o contexto educacional - pode estar associada a alguns fatores como os que listamos a seguir. Um primeiro elemento seria as condições objetivas dos trabalhadores da educação que os torna vulneráveis e presas fáceis de pressões das mais diferentes ordens. A inconsistência da formação recebida seria o segundo elemento. Esta inconsistência não possibilita ao educador desenvolver e construir os instrumentos de análise e crítica necessários para 
o julgamento e a apreciação de inovações nem sempre propostas, algumas vezes sugeridas e, muitas vezes, impostas. $\mathrm{Na}$ confluência dos dois fatores anteriores, localiza-se o significado social da profissão docente que contribui para a difusão de que o trabalho docente é uma tarefa fácil e qualquer um pode executá-la (Maldaner, Schnetzler, 1998) e que aqueles que sabem uma coisa sabem também para ensiná-la (Apel, 1994). Como um quarto elemento, de ordem mais geral, o comportamento dos intelectuais, que são influenciados por numerosos fatores que agem na cultura e na sociedade de seu tempo. "Esses fatores vão desde as visões de mundo e ideologias até às forças econômicas e à tecnologia, passando pelos sistemas de patrocínio e de educação" (Kneller, 1980, p. 205). Neste ponto, as leis que regem os comportamentos dos cientistas não diferem muito das de quaisquer outros grupos sociais (Latour, Woolgar, 1997).

Com uma formação que não favoreceu o desenvolvimento conveniente e necessário na arte de ser educador, o conjunto desses fatores favorece que se recorra aos elementos da representação social que enfatizam não somente os elementos de pressão comportamental, mas também as formas de resistência. $O$ processo de incorporação das novidades não se estabelece linearmente. Por isso, o modismo deixa de ser considerado com uma simples manipulação externa e necessita considerar, na análise, as elaborações dos sujeitos e grupos que, de forma mais ativa ou não, se colocam ante as pressões e as novidades de natureza teórica, onde o escamoteamento é apenas uma das possibilidades (Sá, 1995).

No modismo, o professor muitas vezes possui um desejo real de mudar, mas ingenuamente acredita que uma única ciência, uma única abordagem teórica, uma teoria superficial ou mal compreendida poderá resolver os problemas complexos e multideterminados como os da educação. Visões reducionistas e estreitas - que simplificam o complexo e tomam a parte pelo todo - conduzem, quando muito, a aproximações distorcidas, inócuas e enganadoras.

Esperamos ter demonstrado que as novidades teóricas se constituem modismos quando atuam na exterioridade dos problemas do contexto educativo, facilitando apenas a mudança dos discursos, sem mudarem, na mesma proporção, os resultados e os procedimentos pedagógicos. Para que a proposição de uma inovação educacional não caia no modismo, faz-se necessário demarcar tanto as suas possibilidades quanto seus limites, bem como as suas implicações quando o educador busca implementá-la. Sem esses cuidados, todo o esforço teórico pode cair no vazio.

Se, de um lado, o trabalho formativo exige uma permanente vigilância, de outro, devemos trabalhar para que os educadores possam compreender a problemática educativa dentro de sua complexidade, reunindo forças e se organizando na busca de uma prática coerente com os objetivos da educação, sem perder a dimensão e a natureza da mesma. O trabalho formativo deveria visar ao desenvolvimento de "anticorpos" contra idéias infundadas e simplistas, criando um sistema de alerta permanente, capaz de detectar e imobilizar o ataque dos mais variados tipos de "vírus".

Ao discutirmos a interação dos campos constitutivos do desenvolvimento da arte de compreender as inovações, procuramos defender que os projetos de formação docente devem ser fundamentados nos princípios das ciências da educação e cada vez mais orientados para a prática educativa. Não apenas como uma vontade de governo ou de qualquer grupo de poder, mas contando com a participação efetiva dos educadores a partir da elaboração das propostas.

Do viés temporal entende-se que, entre a atitude que busca novos caminhos ou aquela que permanece nos caminhos conhecidos, existem caminhos intermediários. A simples e pura oposição entre passado/ velho e futuro/novo nos mantêm parados, leva-nos ao caos ou a lugar nenhum. O verdadeiro objetivo da educação é conduzir e completar pessoas situadas geográfica e historicamente, não o de tirá-las da estrada pelas mais diferentes formas de atropelamento ou deixar que fiquem presas, esperando um milagre que as ponha em marcha. Como não existem milagres nem milagreiros, resta-nos a difícil e desafiante arte de nos equilibrar dentro do conflito, dialogando e construindo caminhos alternativos, sem nos refugiar no futuro, que existe apenas virtualmente, ou cristalizar e idolatrar o passado.

É no presente, encruzilhada dos caminhos passados e futuros, entre rotinas, 
novidades e demandas concretas que devemos nos posicionar e construir dialética e dialogicamente novas alternativas. A mentalidade que rejeita estudar o passado ou que o estuda com as viseiras de gurus é a grande adversária da compreensão do presente e dos esforços que empreendemos para tentar mudar a escola atual.

\section{Referências bibliográficas}

APEL, H. J. Teoría y práctica de la educación del maestro. Educación, Tübingen, v. 49/ 50, p. 61-79, 1994.

ARENDT, H. Entre o passado e o futuro. 2. ed. São Paulo: Perspectiva, 1988.

BACHELARD, G. A formação do espirito científico: contribuição para uma psicanálise do conhecimento. Rio de Janeiro: Contraponto, 1996.

BALZAN, N. C. A pesquisa em didática: realidades e propostas. In: CANDAU, V. M. (Org.). A didática em questão. 3. ed. Petrópolis: Vozes, 1985. p. 23-31.

BAUDRILLARD, J. Sociedade de consumo. Lisboa: Edições 70, 1991.

CANDAU, V. M. O papel da didática e a formação de educadores: da exaltação à negação: a busca da relevância. In: Vozes, 1985. p. 12-22. (Org.). A didática em questão. 3. ed. Petrópolis:

CARRAHER, T. N.; CARRAHER, D.; SCHLIEMANN, A. Na vida dez; na escola zero. 6. ed. São Paulo: Cortez, 1991.

CASTELO BRANCO, L. M. O construtivismo e suas implicações pedagógicas. ANDE, São Paulo, v. 10, n. 17, p. 13-19, 1991.

CORAZZA, S. M. Construtivismo: evolução ou modismo? Educação e Realidade, Porto Alegre, v. 21, n. 2, p. 215-232, jul./dez. 1996.

COSTA, M. A escola pública e a moda. Ciência e Cultura, São Paulo, v. 42, n. 5/6, p. 369371, maio/jun. 1990.

COSTA, R. M. Custo Brasil em educação. Revista Brasileira de Política e Administração da Educação, Brasília, v. 13, n. 2, p. 207-220, jul./dez. 1997.

CUNHA, M. V. da. A educação dos educadores: da escola nova à escola de hoje. Campinas: Mercado de Letras, 1995.

DEL NERO, H. S. O sítio da mente: pensamento, emoção e vontade no cérebro humano. São Paulo: Collegium Cognitio, 1997.

FAZENDA, I. C. A. Interdisciplinaridade: história, teoria e pesquisa. 2. ed. Campinas: Papirus, 1999.

FROMM, E. A arte de amar. Belo Horizonte: Itatiaia, 1995.

GARCIA, W. Planejamento e educação no Brasil: a busca de novos caminhos. In: KUENZER, A.; CALAZANS, M. J. C; GARCIA, W. Planejamento e educação no Brasil. 3. ed. São Paulo: Cortez, 1996. p. 35-54.

KNELLER, G. F. A ciência como atividade humana. Rio de Janeiro: Zahar; São Paulo: Edusp, 1980.

LATOUR, B; WOOLGAR, S. A vida de laboratório: a produção dos fatos científicos. Rio de Janeiro: Relume Dumará, 1997. 
LENOIR, Y.; LAROSE, F. Uma tipologia das representações e das práticas da interdisciplinaridade entre os professores do primário no Quebec. Revista Brasileira de Estudos Pedagógicos, Brasília, v. 79, n. 192, p. 48-59, maio/ago. 1998.

MAFRA, N. D. F. O professor se perde a face. Olhar de Professor, Ponta Grossa, v. 1, n. 1, p. 25-28, 1998.

MALDANER, O. A.; SCHNETZLER, R. P. A necessária conjugação da pesquisa e do ensino na formação de professores e professoras. In: CHASSOT, A.; OLIVEIRA, R. J. de. Ciência, ética e cultura na educação. São Leopoldo: Unisinos, 1998. p. 195214.

PUIGGRÓS, A. Voltar a educar. Rio de Janeiro: Agir, 1997.

REGO, T. C. Educação, cultura e desenvolvimento: o que pensam os professores sobre as diferenças individuais. In: AQUINO, J. G. Diferenças e preconceito na escola: alternativas teóricas e práticas. São Paulo: Summus, 1998. p. 49-71.

ROSSO, A. J. O problema da moda na educação. Alcance, Itajaí, v. 1, n. 3, p. 86-105, 1995.

ROSSO, A. J.; ETGES, N. J. O que pensam os professores de Ciências e Matemática da educação? Alcance, Itajaí, v. 6, n. 2, p. 15-25, out. 1999.

SÁ, C. P de. Representações sociais: conceito e o estado atual da teoria. In: SPINK, M. J. (Org.). O conhecimento no cotidiano: representações sociais na perspectiva da psicologia social. São Paulo: Brasiliense, 1995. p. 19-45.

SILVA, Maria Helena G. F. Dias da. O professor e o seu desenvolvimento profissional: superando a concepção de algoz incompetente. Cadernos Cedes, Campinas, v. 19, n. 44, p. 33-45, abr. 1997.

SOLÉ, I.; COLL, C. Os professores e a concepção construtivista. In: COLL, C. et al. O construtivismo na sala de aula. São Paulo: Ática, 1997. p. 9-28.

VÁSQUEZ, A. S. Filosofia da práxis. 3. ed. Rio de Janeiro: Paz e Terra, 1986.

Recebido em 26 de fevereiro de 2001.

Ademir José Rosso, doutor em Educação (Ensino de Ciências Exatas e Naturais) pela Universidade Federal de Santa Catarina (UFSC) é professor do Departamento de Métodos e Técnicas de Ensino da Universidade Estadual de Ponta Grossa (UEPG).

Núbio Delanne Ferraz Mafra, mestre em Educação pela Universidade Federal Fluminense (UFF), é professor do Departamento de Letras Vernáculas e Clássicas da Universidade Estadual de Londrina (UEL).

\section{Abstract}

This paper discusses the problem identified as fashion in the educational context. In discussing the theme, one tries to establish the phenomenon contour, its explicitness with some examples of its occurrence in school context. The fundamental concern is to associate the theme with teacher education and teaching practice, seeking the development of an attitude of research of what is really significant in education.

Keywords: teacher's formation; educational innovations; education. 